\title{
Delayed presentation of a traumatic splenic artery pseudoaneurysm in an initially normal spleen: Case study and review of literature
}

\author{
Qaasim Dollie* \\ Gold Coast University Hospital, Queensland, Australia
}

\author{
Received: March 14, 2018 \\ Accepted: June 21, 2018 \\ Online Published: July 9, 2018 \\ DOI: $10.5430 /$ css.v4n2p1 \\ URL: https://doi.org/10.5430/css.v4n2p1
}

\begin{abstract}
Background: Blunt injury of the spleen is common and with the shift towards nonoperative management in haemodynamically stable patients, the delayed development of splenic artery pseudoaneurysms are of great concern. Management traditionally involves angioembolisation with the intent to preserve splenic function; however recent studies suggest that this is not without complication.

Case presentation: We present a rare case of delayed splenic pseudoaneurysm arising 6 days post motorbike accident, with initial computerised tomography showing no evidence of splenic injury. The patient was successfully embolised and progressed well without complication. No clear cause was found for his development of splenic injury.

Conclusions: Splenic artery pseudoaneurysms are not uncommon and necessitate follow-up imaging after nonoperative management of blunt splenic trauma. Once diagnosed, embolisation versus conservative management can be considered on a case-by-case basis.
\end{abstract}

Key Words: Trauma, Spleen, Embolisation

\section{INTRODUCTION}

The management of blunt splenic injury collectively includes operative intervention, embolisation and nonoperative observation. Over the last few decades observation and embolisation have gained increasing favour in attempt to preserve splenic function. As a consequence, there are obvious concerns for complications resulting from this more conservative approach, including the development of splenic artery pseudoaneurysms (SAP). Guidelines specifically relating to the management of these SAPs are still being defined. We present a case of delayed SAP formation six days post motorbike accident. This is not an uncommon phenomenon itself, however the case is unique in that the patient initially presented without clinical or radiological signs of intraabdominal injury. We will discuss this case and review the literature regarding SAP and their proposed management.

\section{Case presentation}

An otherwise healthy 54-year-old gentleman has a motorbike accident sustaining primarily blunt chest and abdominal wall trauma. He presented to the emergency department GCS 15 and haemodynamically stable. CT pan scan revealed bilateral chest wall fractures (right sided flail with ribs 1 to 10 and left $6^{\text {th }}$ rib) with right sided pneumothorax, right scapula and clavicle fracture and deep patellar laceration, with an Injury Severity Score totalling 25. There was no reported CT

*Correspondence: Qaasim Dollie; Email: qaasimd@gmail.com; Address: Gold Coast University Hospital, Queensland, Australia. 
evidence of blunt splenic trauma on the initial pan scan CT (see Figure 1).

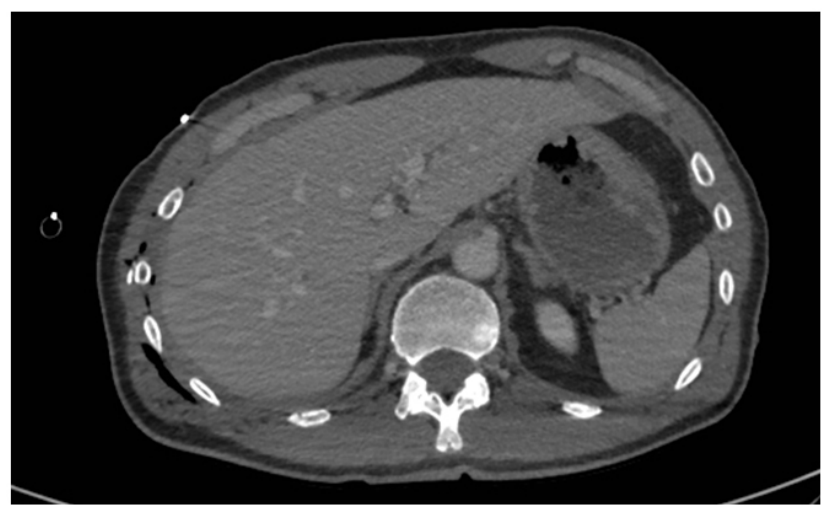

Figure 1. Initial CT pan scan with contrast showing no evidence of blunt splenic trauma

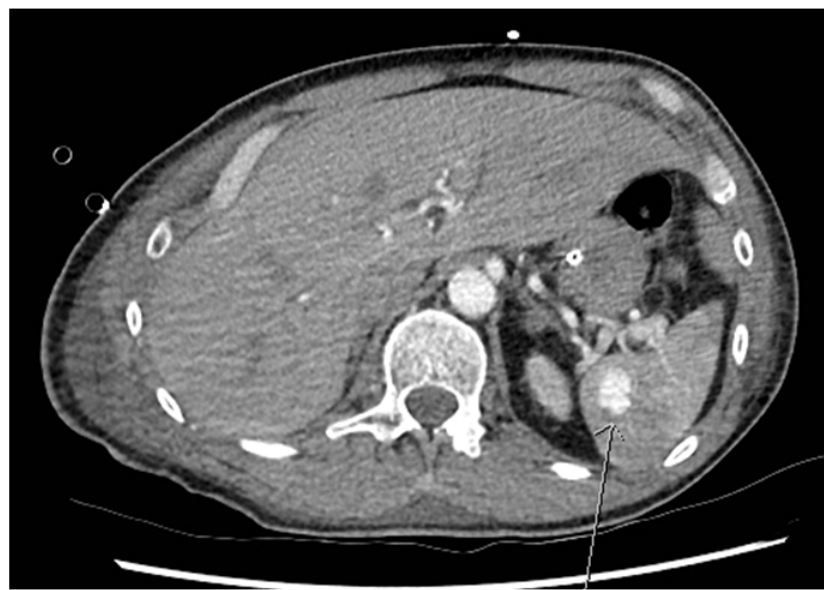

Figure 2. Computerised tomography, arterial phase on day 6 of admission

Arrow depicting a new $2 \mathrm{~cm}$ hyperdense focus in the region of the splenic hilum, suspicious for a pseudoaneurysm

He required right sided intercostal catheter insertion on presentation to the emergency department then admitted to the ICU. Supportive care included patient controlled analgesia, non invasive ventilation and antibiotics. On day 3 the decision was made to proceed to rib $\left(3^{r d}, 4^{\text {th }}\right.$ and $\left.5^{\text {th }}\right)$ and clavicle fixation along with lower limb washout due to ongoing high ventilatory support and analgesia requirements.

Postoperatively he progressed well, however on day 6 of admission his haemoglobin levels fell from $90 \mathrm{~g} / \mathrm{L}$ to $72 \mathrm{~g} / \mathrm{L}$ in 12 hours on routine full blood count. Clinically he remained haemodynamically stable and did not require inotropic support. The primary source of bleed was thought to be most likely from his thorax. However, repeat computerised tomography of his chest was normal. Incidentally a new $2 \mathrm{~cm}$ hyperdense focus was found in the splenic hilum (see Figure 2) which was not present on his initial trauma scan. Even though his initial abdominal examination and investigations were normal the trauma was significant enough to be concerned about splenic injury consistent with a splenic artery pseudoaneurysm.

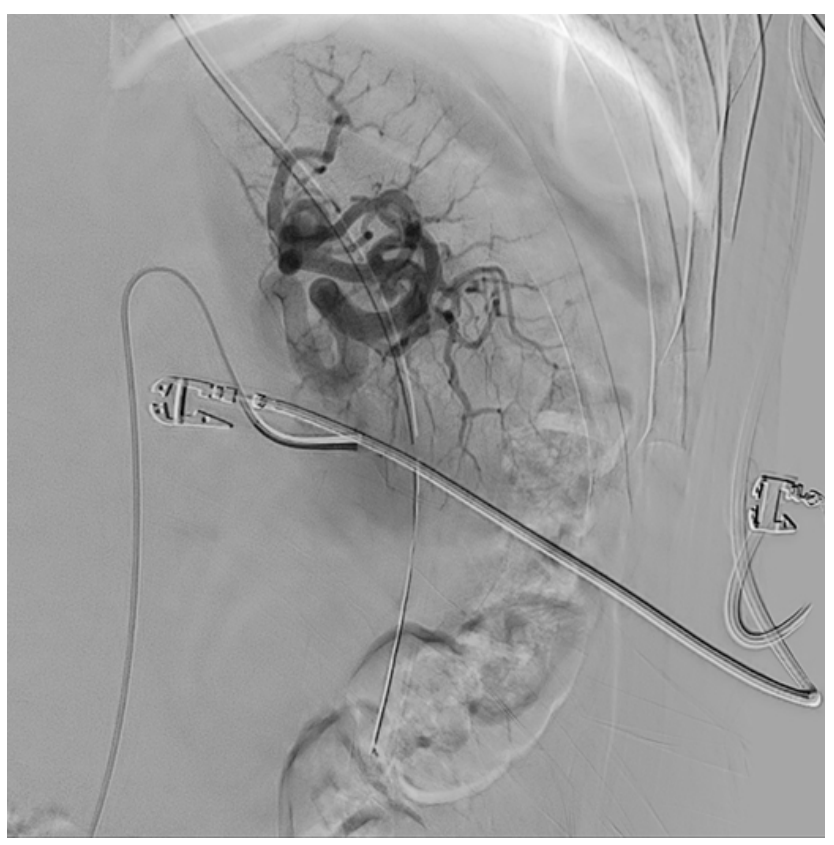

Figure 3. Angiogram depicting the splenic pseudoaneurysm of the upper pole branch of the splenic artery

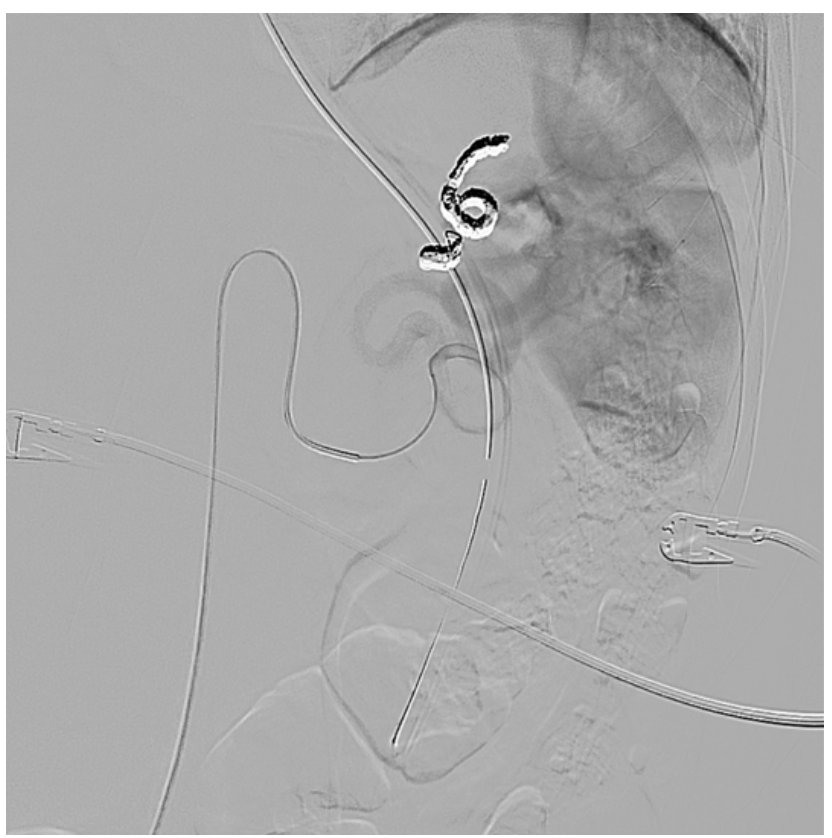

Figure 4. Angiogram depicting the result of the selective embolisation with multiple coils insitu 
The decision was made to proceed with embolisation due to his the size of the SAP along with the fact that the patient remained clinically stable. The upper pole branch of the splenic artery was found to supply the large pseudoaneurysm (see Figure 3). Access was gained via the right common femoral artery. The splenic artery was accesed via microcatheter (Progreat 0.025/0.65 mm) and selectively embolised with coils to upper pole branch (see Figure 4).

The patient also received 2 units of packed red bloods cells and remained in the intensive care for a total of 15 days, primarily due to respiratory issues and ventilator wean. $\mathrm{He}$ recovered well with no abdominal concerns 11 months post incident.

\section{DisCUSSION}

The general management of splenic injury is based on the clinical presentation which includes patient haemodynamic status and the degree of injury on computerised tomography. Unstable patients with splenic injury require splenorrhaphy or splenectomy. In haemodynamically stable patients with splenic injury, the management is not as clear cut, particularly in middle grade splenic lacerations. These cohorts of patients can be considered for nonoperative management versus angioembolisation. Nonoperative management includes admission to a high dependency or intensive care unit, close monitoring of vital signs, strict bed rest, serial abdominal examinations, monitoring of haemoglobin levels and judicious use of repeat imaging.

The indications for splenic artery embolization are based on computerised tomographic evidence of vascular injury (contrast extravasation, pseudoaneurysm or arteriovenous fistula) in conjunction with the clinical picture. ${ }^{[1]}$ The true value of splenic artery embolization remains a point of contention but generally, it is believed to increase the rate of splenic salvage. ${ }^{[2]}$ Embolisation is not without complications: haemorrhage, abscess, infarction, renal failure, migration of coils and local access site complications such as infection, thrombosis. The estimated rates of complication up to $20 \%$ reported with severe complications less than $4 \% .^{[3]}$

Delayed splenic injuries are defined as an injury occurring after 48 hours after the initial insult, eponymously this period is known as the "latent period of Baudet". ${ }^{[4]}$ However, cases exist of delayed splenic rupture presenting months to years after blunt abdominal trauma. ${ }^{[5,6]}$ To note, delayed splenic injury includes: initially missed splenic injury, a delayed presentation of this missed injury or an actual delay of initially minor abdominal injury. This is not a common occurrence with a single centre study reporting 8 cases of minor trauma patients who presented over 48 hours later with

Published by Sciedu Press splenic rupture after minor trauma. Interestingly all patients had co-existent diseases (HIV, cirrhosis, sickle cell disease) that could be associated with "fragile spleen". ${ }^{[7]}$

Computerised tomography is the standard for diagnosing and stratifying the severity of splenic injury since the 1990s. ${ }^{[8]}$ The visualisation of different splenic pathologies however relies on specific phases of contrast for accurate diagnosis. A retrospective series of 120 blunt trauma patients were looked at who had a combination of splenic pathology (parenchymal injury, presence of splenic pseudoaneurysm, active bleed) along with normal spleens on dual-phase abdominal computerised tomography by 6 different radiologists. Arterial phase imaging was found to be more sensitive (70\% vs. $17 \%$ ) and more accurate ( $87 \%$ vs. $72 \%$ ) than portal venous imaging in identifying intra-splenic pseudoaneurysms. Portal venous phase imaging was more sensitive and more accurate for active bleeding and parenchymal injury. ${ }^{[9,10]}$ The initial absence of any evidence of splenic injury could thus be argued due to inappropriate timing of contrast used however the CT trauma panscan included that of portal venous phase (see Figure 1).

Since 1995 the nonoperative management of stable blunt splenic injuries has gathered momentum based on the success of angiographic diagnosis and management. ${ }^{[11]}$ To delineate between successful nonoperative candidates, the Eastern Association for the Surgery of Trauma performed a retrospective multicentre of study over 1,400 cases with blunt splenic injury. They found that $62 \%$ of patients had initial non-operative management. Predictably, the more severe the injury the more likely nonoperative management failed: respectively $75 \%, 70 \%, 49 \%, 17 \%, 1 \%$ for AAST (American Association for the Surgery of Trauma) classes of splenic trauma grades I to $\mathrm{V}$ respectively. Ultimately, the rate of failed observation of nonoperative managed blunt splenic trauma is $10 \%$ with the majority of failures occurring the first 24 hours. ${ }^{[12,13]}$

A true splenic aneurysm develops when all 3 layers of arterial wall dilate and thin but remain intact. A pseudoaneurysm or false aneurysm develops from a tear in the vessel wall with formation of arterial haematoma and is thought to be commonly due to local inflammation. ${ }^{[14]}$ Splenic pseudoaneurysms are one of the complications of nonoperative management of blunt splenic trauma. The earliest retrospective study focussing on SAP looked at 298 patients who had a follow-up CT on day two or three and found $7.7 \%$ of patients developed SAP. ${ }^{[15]}$ Weinberg looked at 411 patients with all with nonoperative management of blunt splenic injury and similarly found a $7.1 \%$ rate of SAP. ${ }^{[16]}$ Leeper found a $6 \%$ rate of SPA and arterial extravasation in patients routinely re-imaged during a 12-year period, suggested routine re- 
imaging of patients regardless of the splenic injury grade. ${ }^{[17]}$

Muroya et al then looked at the incidence and the management of 104 patients that had non operative management of blunt splenic trauma and found 16 patients (15\%) developed SAP ( 7 patients grade II and 9 grade III) and commonly occurs between days 1 to 8 . Interestingly, half of these patients were observed and spontaneously occluded on follow up CT or angiography. ${ }^{[18]}$ Recently, Morrison et al found also reproduced a similar rate of $7 \%$ ( 9 out of 133 cases) with the majority of patients having a severity grade of III or more. 3 of the patients were diagnosed on initial scan and embolised whereas 6 were found on repeat imaging, ${ }^{[19]}$ reinforcing the importance of repeat imaging.

It is not clear why on initial presentation why there was no evidence of splenic injury. Our patient's Injury Severity Score was significant involving chest wall trauma which may well have been distracting and thus his injury may have been an evolving process. He was otherwise healthy, unremarkable abdominal examination, focussed assessment with ultrasound and normal appearing spleen on computeried tomography ( $82 \mathrm{~mm}$ antero-posterior length on axial) going against the argument for a "fragile spleen". Furthermore, he was observed in the intensive care setting from admission right through to the diagnosis of his SAP. The diagnosis in this case is heavily based on imaging and as discussed, the use of incorrect phase of contrast may have played a role in clouding the presence of an initial insult. Severe coagulopathy or inflammation resulting in splenic rupture has been documented ${ }^{[20]}$ and is possible in the context of the trauma patient but his coagulation profile (INR 1.1) along with ROTEM (Rotational thromboelastometry) and platelet function studies were unremarkable on presentation.

\section{Conclusions}

Splenic pseudoaneurysms are not an uncommon by product of nonoperative management of splenic injuries. The review of data found the rates of SAP to be present in around $7 \%-15 \%$ of patients on repeat imaging. This is supportive of routine rescanning patients with splenic grade injuries of III or above. Recent data suggests that angioembolisation should not automatically be performed after their diagnosis and rather the approach should be case based allowing for the consideration of nonoperative management.

\section{CONFLiCTS OF INTEREST Disclosure}

The author declares he has no conflicts of interest.

\section{REFERENCES}

[1] Olthof DC, Vlies CHVD, Goslings JC. Evidence-Based Management and Controversies in Blunt Splenic Trauma. Current Trauma Reports. 2017; 3(1): 32-37. PMid: 28303214. https://doi.org/10.100 7/s40719-017-0074-2

[2] Van Der Vlies CH, Hoekstra J, Ponsen KJ, et al. Impact of splenic artery embolization on the success rate of nonoperative management for blunt splenic injury. Cardiovascular \& Interventional Radiology. 2012; 35(1): 76. PMid: 21431976. https://doi.org/10.1007/ s00270-011-0132-z

[3] Frandon J, Rodière M, Arvieux C, et al. Blunt splenic injury: outcomes of proximal versus distal and combined splenic artery embolization. Diagnostic \& Interventional Imaging. 2014; 95(9): 82531. PMid: 24746759. https://doi.org/10.1016/j.diii. 201 4.03 .009

[4] BAUDET R. Ruptures de la rate. Med Practique. 1907; 3.

[5] Resteghini N, Nielsen J, Hoimes ML, et al. Delayed splenic rupture presenting 70 days following blunt abdominal trauma. Clinical Imaging. 1900; 38(1): 73-4. PMid: 24139835. https ://doi.org/10.1 016/j.clinimag. 2013.09.003

[6] Fernandes CM. Splenic Rupture Manifesting Two Years after Diagnosis of Injury. Academic Emergency Medicine. 1996; 3: 946-947. PMid: 8891041. https://doi.org/10.1111/j.1553-2712.19 96. $\mathrm{tb} 03324 . \mathrm{x}$

[7] Parithivel VS, Sajja SB, Basu A, et al. Delayed presentation of splenic injury: still a common syndrome. International Surgery. 2002; 87(2): 120. PMid: 12222914.
[8] Moore EE, Cogbill TH, Jurkovich GJ, et al. Organ injury scaling: spleen and liver (1994 revision). Journal of Trauma \& Acute Care Surgery. 1995; 38(3): 323-324. https://doi.org/10.1097/00 005373-199503000-00001

[9] Boscak AR, Shanmuganathan K, Mirvis SE, et al. Optimizing trauma multidetector CT protocol for blunt splenic injury: need for arterial and portal venous phase scans. Radiology. 2013; 268(1): 7988. PMid: 23449955 . https://doi.org/10.1148/radiol.131 21370

[10] Holly BP, Steenburg SD. Multidetector CT of blunt traumatic venous injuries in the chest, abdomen, and pelvis. Radiographics. 2011; 31(5): 1415. PMid: 21918052. https://doi.org/10.1148/rg .315105221

[11] Sclafani SJ, Shaftan GW, Scalea TM, et al. Nonoperative salvage of computed tomography-diagnosed splenic injuries: utilization of angiography for triage and embolization for hemostasis. Journal of Trauma. 1995; 39(5): 818. PMid: 7473996. https://doi.org/10 .1097/00005373-199511000-00004

[12] Peitzman AB, Heil B, Rivera L, et al. Blunt Splenic Injury in Adults: Multi-institutional Study of the Eastern Association for the Surgery of Trauma. Journal of Trauma and Acute Care Surgery. 2000; 49: 177-189. https://doi.org/10.1097/00005373-200 008000-00002

[13] Stassen NA, Bhullar I, Cheng JD, et al. Selective nonoperative management of blunt splenic injury: an Eastern Association for the Surgery of Trauma practice management guideline. Journal of Trauma \& Acute Care Surgery. 2012; 73(5 Suppl 4): S288. PMid: 
23114483. https://doi.org/10.1097/TA.0b013e318270160

[14] Al-Habbal Y, Christophi C, Muralidharan V. Aneurysms of the splenic artery - A review. Surgeon Journal of the Royal Colleges of Surgeons of Edinburgh \& Ireland. 2010; 8(4): 223-231. PMid: 20569943. https://doi.org/10.1016/j.surge.2009.11.01 1

[15] Davis KA, Fabian TC, Croce MA, et al. Improved success in nonoperative management of blunt splenic injuries: embolization of splenic artery pseudoaneurysms. Journal of Trauma \& Acute Care Surgery. 1998; 44(6): 1008-1013. https://doi.org/10.1097/00005373 $-199806000-00013$

[16] Weinberg JA, Lockhart ME, Parmar AD, et al. Computed tomography identification of latent pseudoaneurysm after blunt splenic injury: pathology or technology? Journal of Trauma \& Acute Care Surgery. 2010; 68(5): 1112-1116. PMid: 20453766. https: //doi.org/10.1097/TA.0b013e3181d769fc
[17] Leeper WR, Leeper TJ, Ouellette D, et al. Delayed hemorrhagic complications in the nonoperative management of blunt splenic trauma: early screening leads to a decrease in failure rate. J Trauma Acute Care Surg. 2014; 76(6): 1349-1353. PMid: 24854299. https : //doi.org/10.1097/TA.0000000000000228

[18] Muroya T, Ogura H, Shimizu K, et al. Delayed formation of splenic pseudoaneurysm following nonoperative management in blunt splenic injury: Multi-institutional study in Osaka, Japan. Journal of Trauma \& Acute Care Surgery. 2013; 75(3): 417. PMid: 24089111. https://doi.org/10.1097/TA.0b013e31829fda7 7

[19] Morrison CA, Gross BW, Kauffman M, et al. Overview of Nonoperative Blunt Splenic Injury Management with Associated Splenic Artery Pseudoaneurysm. American Surgeon. 2017; 83(6): 554. PMid: 28637555.

[20] Renzulli P, Hostettler A, Schoepfer AM, et al. Systematic review of atraumatic splenic rupture. British Journal of Surgery. 2009; 96(10): 1114-21. PMid: 19787754. https://doi.org/10.1002/bjs. 67 37 